\title{
Removal of Anionic Dye in Acid Solution by Self Crosslinked Insoluble Dendronized Chitosan
}

\author{
Kishor Sarkar, Sovan Lal Banerjee and PP Kundu*
}

Department of Polymer Science \& Technology, University of Calcutta, 92, A. P. C. Road, Kolkata-9, India

\begin{abstract}
Insoluble Dendronized Chitosan (DCTS) was prepared to improve the adsorption capacity of chitosan (CTS) as well as to lower its solubility at lower $\mathrm{pH}$ for efficient removal of acid dye, Acid Blue 9 (AB 9) from aqueous solutions. Dendronized chitosan was prepared by grafting 'dendrimer-like' Polyamidoamine (PAMAM) onto CTS surface using Michael addition reaction followed by amidation reaction. The obtained CTS derivative became insoluble at any $\mathrm{pH}$ medium due to self inter- and intra-molecular cross linking during the reaction without any external crosslinker. The adsorption capacity of the CTS derivative was studied using batch method with respect to various parameters like, initial $\mathrm{pH}$ of the dye solution, initial dye concentration, adsorption temperature and adsorption time. The batch study showed that the adsorption capacity of CTS derivative increased many times than that of chitosan. From the adsorption kinetic study, it was found that the adsorption of dye molecule on the a3

Dsorbent surface obeyed pseudo-second-order kinetic instead of generally reported pseudo-first-order kinetic The adsorption equilibrium showed that the Langmuir equation represented best fit of the experimental data than that of Freundlich equation. The desorbed DCTS could be reused for the adsorption of the acid dyes. The results in this study showed that DCTS may be an attractive candidate for removing anionic dyes from the wastewater.
\end{abstract}

Keywords: Chitosan; Dendrimer; Adsorption; Acid blue 9; Kinetics.

\section{Introduction}

During the last few years, the environment has been largely polluted by industrial effluents containing dyes. There are almost hundred thousand of commercially available dyes and more than $7 \times 10^{5}$ tons dyes are produced annually [1]. Large quantities of dyes are used as well as emitted into effluents from various industries like textile, food, paper and plastic industries [2]. The colored dye effluents are considered to be highly toxic to the aquatic biota and as a result, the colorization of water affects the symbiotic process by disturbing the natural equilibrium by reducing photosynthetic activity and primary production [3]. The dyes are also biologically non-degradable because of their synthetic origins and their mainly aromatic structures [4]. Therefore, it is desirable to remove coloring dye material from wastewater due to their possible toxicity, carcinogenicity and resistant to environmental conditions like, light, $\mathrm{pH}$ and microbial attack.

During the past three decades, several methods including coagulation and flocculation [5], membrane separation [6], electrocoagulation [7] and adsorption on activated carbon, manganese, silica gel and clays [8] have been used for the removal of colored dyes from wastewater. Among these methods, most widely used technique is adsorption process for the decontamination of the dye-containing effluents. Currently, activated carbon is the most widely used commercial adsorbent due to its excellent adsorption capacity [9]. But, high cost and regeneration difficulty are the major drawbacks for the commercial use of activated carbon as adsorbent [10]. To overcome these problems, most researchers have been focused on the development of low cost and effective new adsorbents [11]. In recent years, many works on lowcost adsorbents have been studied for dye removal, such as cotton [12], guava leaf powder [13], rice husk [14], and chitosan [15].

Natural polymeric compounds are currently most widely used materials because they are renewable, biodegradable, non-toxic and potential as an environmentally friendly material [16]. Chitosan is the most attractive polymer among the natural polymeric materials due to its low cost and readily availability. Chitosan is a linear copolymer composed of (1-4)-linked D-glucosamine and $N$-acetyl-D-glucosamine and is obtained by alkaline hydrolysis of chitin (second abundant polymer in nature after cellulose) [17]. Chitosan is widely used as a wellknown adsorbent for the removal of heavy, transition metals and dyes [18]. Chitosan adsorbs acid dyes by electrostatic attraction because of its cationic character through protonation of the amino groups in acidic aqueous solutions. But, CTS is soluble in acidic media and therefore it cannot be used as an insoluble adsorbent for removal of acid dyes from acid effluents [21]. Therefore, researchers showed interest in chemical modification of CTS to enhance their stability at low $\mathrm{pH}$ solution and consequently their potential applications as adsorbent [19]. Many researchers modified chitosan by crosslinking using different types of cross-linkers like, Epichlorohydrine (ECH) [22], glutaraldehyde [23], tripolyphosphate [24] and sulfuric acid [25] to improve its stability at acidic solution for anionic dye adsorption.

In this work, we prepared insoluble dendronized chitosan from CTS surface by divergent process without using any external cross-linking agent. The obtained insoluble dendronized chitosan was then used to remove $\mathrm{AB} 9$ from aqueous solution by batch adsorption process. The influence of different parameters including, $\mathrm{pH}$, temperature, time and initial dye concentration on adsorption capacity of DCTS was studied. The Langmuir and Freundlich equations were used to fit the equilibrium isotherms. In addition to this, Attenuated Total Reflection (ATR) FTIR and inverted microscopy are used to confirm the adsorption of dye

*Corresponding author: PP Kundu, Department of Polymer Science \& Technology, University of Calcutta, 92, A. P. C. Road, Kolkata-9, India, E-mail: ppk922@gmail.com

Received March 29, 2012; Accepted May 17, 2012; Published May 23, 2012

Citation: Sarkar K, Banerjee SL, Kundu PP (2012) Removal of Anionic Dye in Acid Solution by Self Crosslinked Insoluble Dendronized Chitosan. Hydrol Current Res 3:133. doi:10.4172/2157-7587.1000133

Copyright: ( 2012 Sarkar K, et al. This is an open-access article distributed under the terms of the Creative Commons Attribution License, which permits unrestricted use, distribution, and reproduction in any medium, provided the original author and source are credited. 
onto chitosan derivative. Desorption study of adsorbed DCTS was also carried out by using $\mathrm{NaOH}$ as desorption agent.

\section{Methods}

\section{Materials}

Chitosan was purchased from Acros Organics, USA. The degree of deacetylation (determined by potentiometric titration) and weight average molecular weight (determined by Gel Permeation Chromatography, Waters, USA) were $86 \%$ and $222 \mathrm{kDa}$, respectively. Ethylenediamine (EDA), Methyl Acrylate (MA) and methanol were purchased from Merck, India. Double distilled water was prepared in our laboratory using Water Distillation System (Cat. No-3362-4.0L, BOROSIL, India). All of the other reagents used were of analytical reagent grade.

\section{Dye stock solution}

Acid blue 9 was used in this study as model anionic dye. It is also known as brilliant blue, $\lambda_{\max }=630 \mathrm{~nm}$. AB 9 was purchased from Himedia Laboratories Pvt. Ltd., India. The molecular formula, molecular mass and purity of $\mathrm{AB} 9$ are $\mathrm{C}_{37} \mathrm{H}_{34} \mathrm{~N}_{2} \mathrm{O}_{9} \mathrm{~S}_{3} \mathrm{Na}_{2}, 792.86$ and $\sim 70 \%$ respectively. Acid blue 9 stock solution of $3000 \mathrm{mg} / \mathrm{L}$ was prepared by dissolving $3.0 \mathrm{~g}$ of the dye into $1000 \mathrm{ml}$ double distilled water. The $\mathrm{pH}$ of the dye solution was adjusted by dilute $\mathrm{HCl}$ or $\mathrm{NaOH}$. The stock solution was used throughout the whole experiment by fresh dilution.

\section{Preparation of insoluble dendronized chitosan}

The dendronized chitosan was prepared according to the previous method [26] but with slight modification. Dendronized chitosan was prepared by following two consecutive steps such as (i) Michael addition step and (ii) amidation reaction step. In the Michael addition step, MA groups were attached with the surface amino groups of CTS. Briefly, $25 \mathrm{~mL}$ of MA was added to a $250 \mathrm{~mL}$ flask containing $5.0 \mathrm{~g}$ of CTS powder under nitrogen atmosphere and was swollen for $4 \mathrm{hr}$ with $40 \mathrm{~mL}$ methanol. Then, the mixture was stirred with a magnetic stirrer at $40^{\circ} \mathrm{C}$ for 4 days. After that, the solid product was filtered off, washed with $\mathrm{MeOH}$ and purified by Soxhlet extraction with $\mathrm{EtOH}$ for $12 \mathrm{hr}$. Ester terminated $(0.5 \mathrm{G})$ dendronized chitosan was obtained by drying under vacuum at $50^{\circ} \mathrm{C}$ over $24 \mathrm{hr}$.

In the second step, amine terminated $(1.0 \mathrm{G})$ dendronized chitosan was prepared via the amidation reaction of ester terminated DCTS with EDA. Briefly, $15 \mathrm{~mL}$ of EDA was added to a $250 \mathrm{~mL}$ flask containing $3.0 \mathrm{~g}$ of ester terminated DCTS under nitrogen atmosphere and was swollen for $4 \mathrm{hr}$ by $30 \mathrm{~mL} \mathrm{MeOH}$. The mixture was then stirred with a magnetic stirrer at $40^{\circ} \mathrm{C}$ for 6 days. Then, the solid product was filtered off, washed with $\mathrm{MeOH}$ and purified by Soxhlet extraction with EtOH for $12 \mathrm{hr}$. Amine terminated $(1.0 \mathrm{G})$ dendronized chitosan was obtained by drying under vacuum at $50^{\circ} \mathrm{C}$ over $24 \mathrm{hr}$.

The above two steps were repeated to prepare $2.0 \mathrm{G}$ amine terminated dendronized chitosan. The ideal synthetic routes of esterand amine-terminated DCTS are illustrated in Scheme 1.

\section{Determination of grafting percentage}

The grafting percentage of dendrimer onto the surface of CTS was determined by the following equation:

Grafting $(\%)=\left(\frac{A-B}{B}\right) \times 100$

Where, $\mathrm{A}$ is the weight of the grafted polymer and $\mathrm{B}$ is the weight of CTS charged.
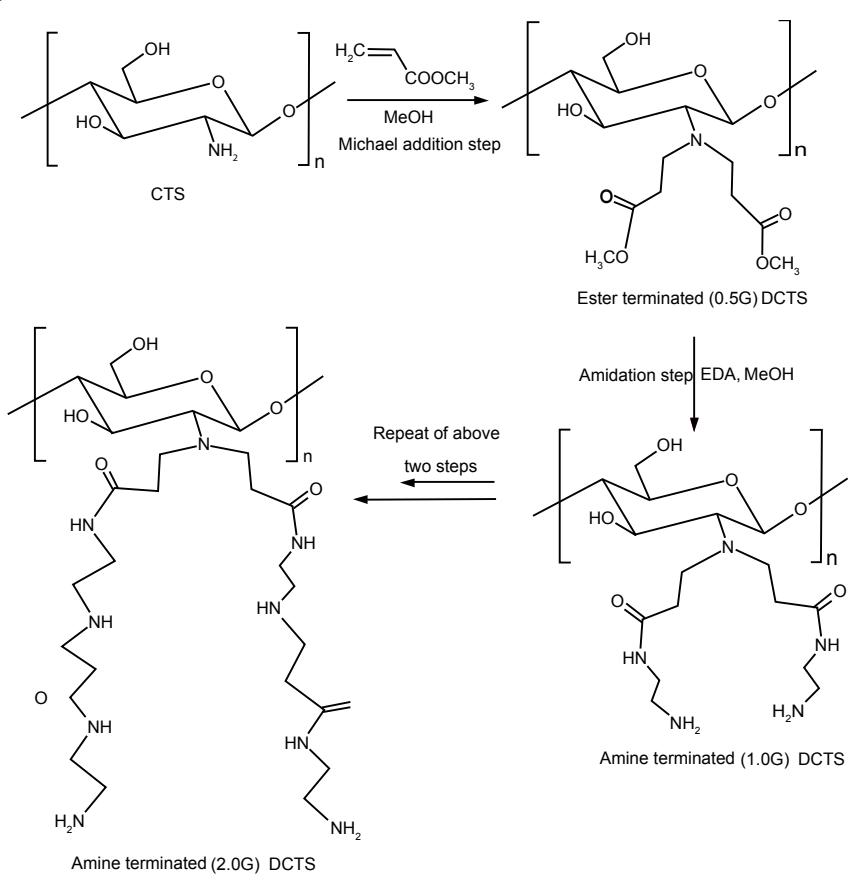

Scheme 1: : Illustrations of intra- and intergroup crosslinking of chitosan derivative.

\section{Characterization of dendronized chitosan}

Dendronized chitosan was characterized by infrared (FT-IR) spectrophotometer. The infrared spectra were recorded at the frequency range of $4000-500 \mathrm{~cm}^{-1}$ with 42 consecutive scans at a $4 \mathrm{~cm}^{-1}$ resolution on a Bruker Alpha ATR FT-IR spectrometer.

\section{Adsorption studies of $A B 9$ by batch technique}

Adsorption kinetics and isotherms were carried out by batch technique. All the batch experiments were carried out on water bath and stirring with a magnetic stirrer at a speed of $120 \mathrm{rpm}$. Amine terminated $(2.0 \mathrm{G})$ dendronized chitosan was used as adsorbent throughout the whole study. In each experiment, a fixed mass of DCTS (50 mg) was added into $25 \mathrm{ml}$ of an aqueous solution of AB 9 at a known concentration in a $250 \mathrm{ml}$ conical flask. The effect of initial dye concentrations on the adsorption was carried out at $30^{\circ} \mathrm{C}$ for $4 \mathrm{hr}$. The influence of $\mathrm{pH}$ on $\mathrm{AB} 9$ removal was studied by adjusting $\mathrm{AB}$ 9 solutions $(2600 \mathrm{mg} / \mathrm{L})$ to different $\mathrm{pH}$ values $(2.0,4.0,6.0,8.0$ and 10.0) using $\mathrm{pH}$ meter at $30^{\circ} \mathrm{C}$ for $4 \mathrm{hr}$. The effect of temperature on dye adsorption was carried out at different temperatures $\left(30^{\circ} \mathrm{C}, 40^{\circ} \mathrm{C}, 50^{\circ} \mathrm{C}\right.$ and $\left.60^{\circ} \mathrm{C}\right)$ in $25 \mathrm{~mL}$ of dye solution $(2600 \mathrm{mg} / \mathrm{L}, \mathrm{pH} 4.0)$ with $50 \mathrm{mg}$ of DCTS for $4 \mathrm{hr}$. For kinetic study, $2600 \mathrm{mg} / \mathrm{L}$ dye solution $(25 \mathrm{~mL}$, $\mathrm{pH} 4.0$ ) was agitated with $50 \mathrm{mg}$ of adsorbent at $30^{\circ} \mathrm{C}$ for $4 \mathrm{hr}$. Batch equilibrium adsorption experiments were carried out by agitating 25 $\mathrm{mL}$ of various dye concentrations of $\mathrm{AB} 9$ solution at $\mathrm{pH} 4.0$ with $50 \mathrm{mg}$ of adsorbent at $30^{\circ} \mathrm{C}$ until equilibrium was established.

For kinetic study, the samples were withdrawn from the flask at predetermined time intervals. The absorbencies of the samples were measured using a UV-vis spectrophotometer (LAMBDA 25, PerkinElmer) at $630 \mathrm{~nm}$ corresponding to a maximum absorbency of $\mathrm{AB} 9$. The amount of adsorption, $q(\mathrm{mg} / \mathrm{g})$ was calculated by the following equation

$$
q=\frac{\left(C_{0}-C_{t}\right) V}{W}
$$


Where, $C_{0}$ and $C_{t}(\mathrm{mg} / \mathrm{L})$ are the concentrations of dye at initial and at time $t$, respectively. $V$ is the volume of solution (L) and $W$ is the mass of dry adsorbent used (g).

\section{Desorption study}

For the desorption studies, $50 \mathrm{mg}$ of DCTS was loaded with AB 9 using $25 \mathrm{~mL}$ of $2600 \mathrm{mg} / \mathrm{L} \mathrm{AB} 9$ solution at $\mathrm{pH}$ 4.0. Agitation period was $180 \mathrm{~min}$ and agitation rate was fixed at $200 \mathrm{rpm}$. AB 9-loaded DCTS was collected by centrifugation and gently washed with distilled water to remove any unadsorbed $\mathrm{AB}$ 9. The amount of $\mathrm{AB} 9$ adsorbed per gram of DCTS was determined by using the supernatant of $\mathrm{AB} 9$ solution. The loaded DCTS was agitated with $25 \mathrm{~mL} 0.2 \mathrm{M} \mathrm{NaOH}$ solution ( $\mathrm{pH}$ 12.0) at $30^{\circ} \mathrm{C}$ for $2 \mathrm{hr}$ and the sample was collected at different time intervals for determination of the eluted dye concentration to calculate the percentage of desorption.

\section{Results and Discussion}

\section{Solubility of chitosan derivative}

It is well known that CTS is soluble in aqueous acidic solution. The solubility of CTS derivatives in acidic media decreased with increasing the grafting percentage of dendrimer onto the surface of CTS. Therefore, the grafting percentage was a critical factor for obtaining insoluble CTS derivatives. It was found that the solubility decreased significantly with an increase in graft content. It was also noticed that low generation ester-terminated $(0.5 \mathrm{G})$ and amine-terminated (1.0) DCTS were partly soluble in $2 \%$ acetic acid at the grafting content of $13.4 \%$ and $30.6 \%$, respectively. But, the higher generation ester-terminated (1.5 $\mathrm{G}$ ) and amine-terminated (2.0) DCTS were insoluble in 2\% acetic acid at the grafting content of $42.6 \%$ and $53.4 \%$, respectively (Table 1 ). The insolubility of DCTS could be explained by the formation of intra- and inter- group cross-linking product, which is depicted in Scheme 2. In Scheme 2, the cross-linking product I could be formed by the side reaction of the ester group with the adjacent amine group during the Michael addition reaction and the product II could be obtained by the side reaction of one equivalent of EDA with two molecules of ester groups.

\section{FT- IR spectra of chitosan derivatives}

Figure 1 shows the FTIR spectra of CTS and its derivatives. Figure 1a shows the basic characteristic peaks of CTS at: $3346.97 \mathrm{~cm}^{-1}(\mathrm{O}-\mathrm{H}$ stretch and N-H stretch, overlap), 2921.85 and $2876.17 \mathrm{~cm}^{-1}(\mathrm{C}-\mathrm{H}$ stretch), $1635.57 \mathrm{~cm}^{-1}$ (NH-CO (I) stretch), $1538.57 \mathrm{~cm}^{-1}$ (N-H bend), $1151.14 \mathrm{~cm}^{-1}$ (bridge-O- stretch) and $1061.33 \mathrm{~cm}^{-1}$ (C-O stretch). In the IR spectrum of ester terminated (1.5G) dendronized chitosan (Figure $1 \mathrm{~b}$ ), the strong peak at $1721.62 \mathrm{~cm}^{-1}$ suggested the presence of ester groups $\left(-\mathrm{CO}_{2} \mathrm{CH}_{3}\right)$. The characteristic absorption peaks of ester groups disappeared in the corresponding amine-terminated $(2.0 \mathrm{G})$ dendronized chitosan, indicating that the ester groups were converted into amine-terminated products (Figure 1c). The intensity of the absorption peak of amine-terminated chitosan derivative at 1641.92

\begin{tabular}{|c|c|c|}
\hline Generation & Grafting (\%) & Soluble part (\%) in 2\% acetic acid \\
\hline 0 & 0 & 100 \\
\hline 0.5 & 13.4 & 85.4 \\
\hline 1.0 & 30.6 & 25.6 \\
\hline 1.5 & 42.6 & 0 \\
\hline 2.0 & 53.4 & 0 \\
\hline
\end{tabular}

Table 1: Grafting percentage of dendronized CTS and their solubility in aqueous acetic acidic solution.

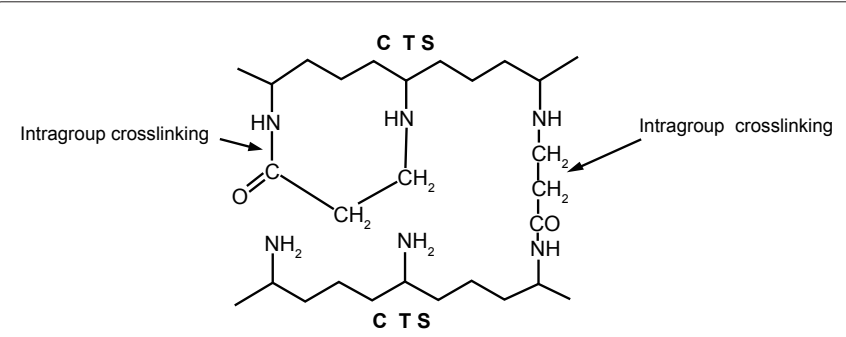

Crosslinking Product 1

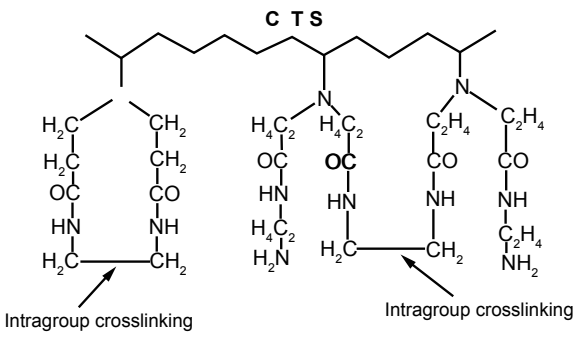

Crosslinking Product 11

Scheme 2: The ideal synthetic routes of ester- and amino-terminated PAMAM-grafted CTS.

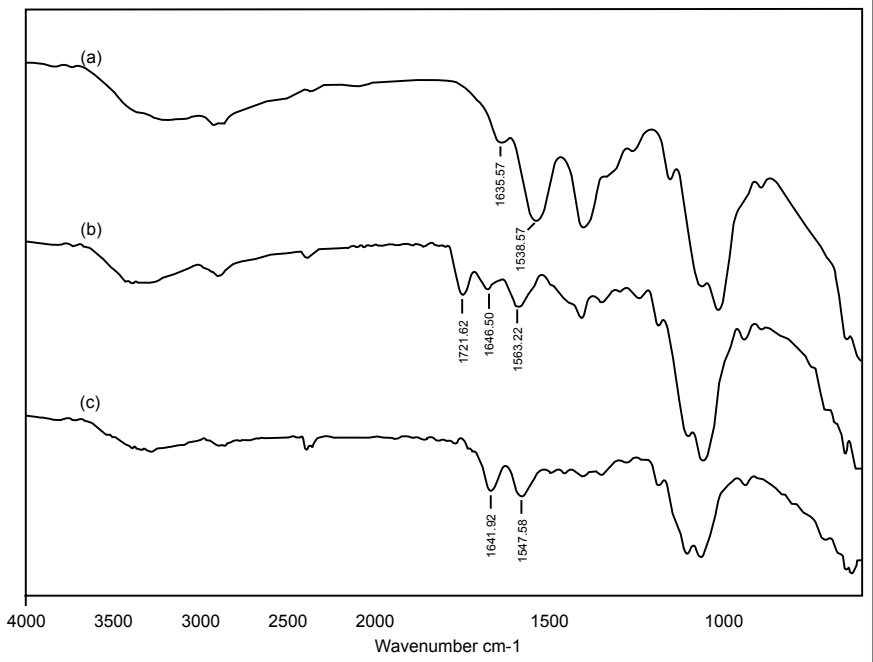

Figure 1: FT-IR spectrum of CTS (a), ester terminated CTSD (b) and amine terminated CTSD (c).

$\mathrm{cm}^{-1}$ for primary amino groups increased compared to that of chitosan, indicating the formation of amine-terminated dendronized chitosan [26]. The absorption peaks at 2866.84 and $2922.12 \mathrm{~cm}^{-1}$, which is characteristic of the methylene group and the peak at $1026.17 \mathrm{~cm}^{-1}$ is the characteristic of tertiary amine group. From these IR spectra, it may be concluded that dendritic polyamidoamine was propagated from the surface of CTS by repeating reaction with MA and EDA.

\section{Effect of $\mathrm{pH}$ on adsorption}

The $\mathrm{pH}$ of the aqueous solution is an important factor during dye separation, as it affects the surface charge of the adsorbent material as well as the degree of ionization of the dye molecule [27]. Therefore, the adsorption experiments were carried out at different $\mathrm{pH}$ values 

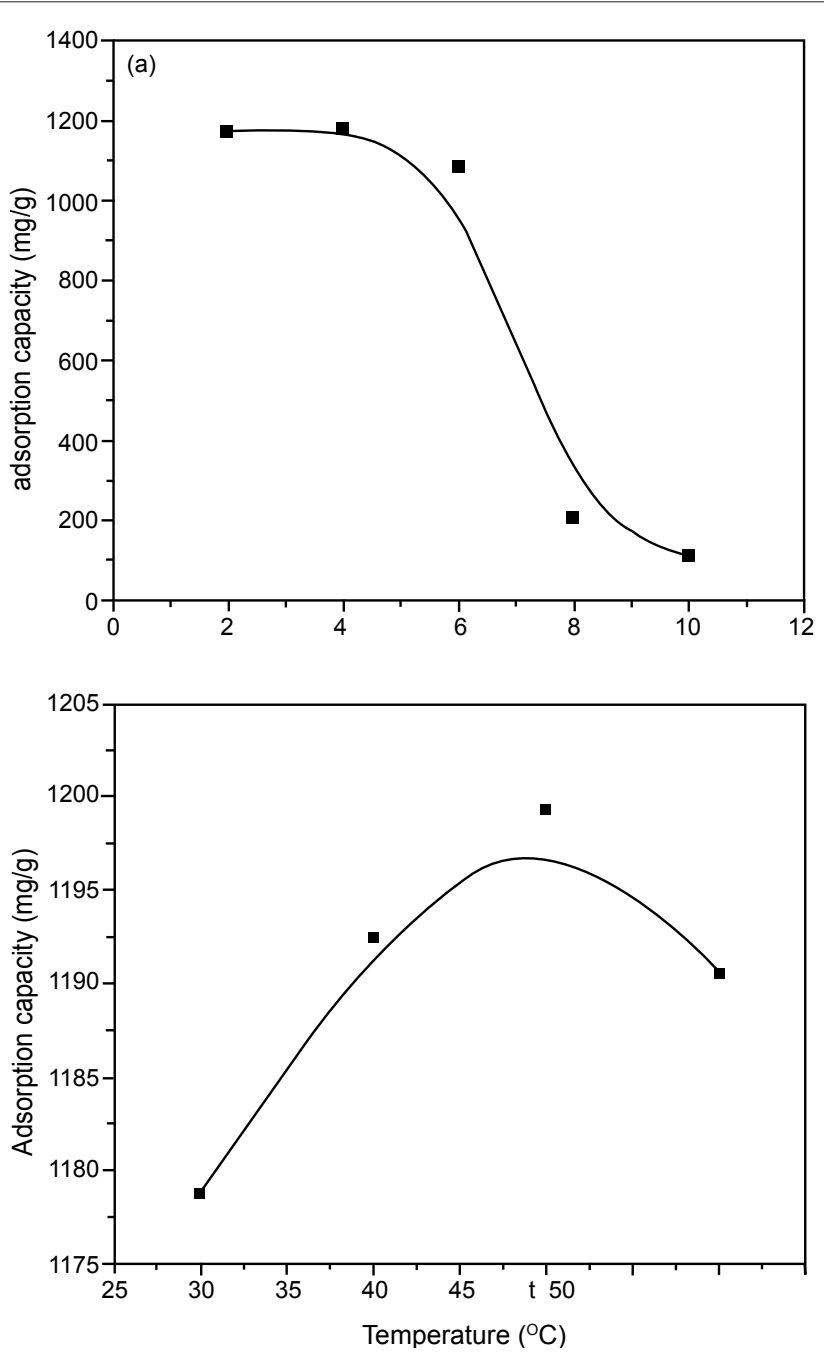

Figure 2: Effect of $\mathrm{pH}$ of the dye solution on adsorption capacity of ATCTSD for $A B 9$ (a) and Effect of reaction temperature on adsorption capacity of ATCTSD for AB 9 (b).

between 2 and 10 to evaluate the effect of the $\mathrm{pH}$ of the dye solution on the adsorption capacity of DCTS. Figure 2a shows the effect of $\mathrm{pH}$ variations on the $\mathrm{AB} 9$ adsorption from the aqueous solutions, for initial AB 9 concentration of $2600 \mathrm{mg} / \mathrm{L}$ and $50 \mathrm{mg}$ of dry DCTS as adsorbent at $30^{\circ} \mathrm{C}$ for $4 \mathrm{hr}$. From Figure $2 \mathrm{a}$, it is found that the adsorption capacity of DCTS sharply increased from $110.14 \mathrm{mg} / \mathrm{g}$ to $1081.46 \mathrm{mg} / \mathrm{g}$ when the solution $\mathrm{pH}$ decreased from 10 to 6 . In the $\mathrm{pH}$ range from 6 to 4 , a slight increase in the adsorption capacity (from $1081.46 \mathrm{mg} / \mathrm{g}$ to $1178.45 \mathrm{mg} / \mathrm{g}$ ) of DCTS was observed. A little decrease in dye adsorption between $\mathrm{pH}$ 4.0 and 2.0 was insignificant. The optimum $\mathrm{pH}$ for dye adsorption by DCTS was found to be 4.0. At low $\mathrm{pH}$, most of the amine groups $\left(-\mathrm{NH}_{2}\right)$ are protonated, which is necessary for the attraction of anionic sulfonic groups of the dye molecule. The similar result was also reported by Chiou and Li [22] and Kamari et al. [28]. The adsorption was drastically decreased after $\mathrm{pH}$ reached at 6.0. This could be explained by the fact that at high $\mathrm{pH}$, more hydroxyl groups $\left(\mathrm{OH}^{-}\right)$are available in solution to compete with the anionic sulfonic groups of $\mathrm{AB} 9$ for the adsorption sites of the polymer, leading to a decrease in the number of adsorption sites for anionic $\mathrm{AB} 9$ dye molecule.

\section{Effect of temperature on adsorption}

The effect of temperature on adsorption capacity of DCTS was investigated at different temperatures such as $30^{\circ} \mathrm{C}, 40^{\circ} \mathrm{C}, 50^{\circ} \mathrm{C}$ and $60^{\circ} \mathrm{C}$ using $50 \mathrm{mg}$ of adsorbent (DCTS) at $\mathrm{pH} 4.0$. Figure $2 \mathrm{~b}$ shows that the adsorption capacity of AB 9 on DCTS increased from 1178.79 $\mathrm{mg} / \mathrm{g}$ to $1199.28 \mathrm{mg} / \mathrm{g}$ with an increase in temperature from $30^{\circ} \mathrm{C}$ to $50^{\circ} \mathrm{C}$. This result suggests that the adsorption of $\mathrm{AB} 9$ on DCTS was endothermic in nature. This may be explained by the fact that the DCTS may be swollen with increasing temperature, facilitating the penetration of dye molecules into the internal structure of DCTS [29]. This phenomenon also leads to an increment in the availability of active surface sites, increased porosity and in the total pore volume of the adsorbent. But, the adsorption capacity slightly decreased from $1199.28 \mathrm{mg} / \mathrm{g}$ to $1190.62 \mathrm{mg} / \mathrm{g}$ with increasing the temperature from $50^{\circ} \mathrm{C}$ to $60^{\circ} \mathrm{C}$. This may be attributed by the fact that the mobility of the dye molecule increases with increasing the temperature, which may responsible for the decrease of adsorption capacity of dendronized chitosan. The similar result was reported in the previous study [30].

\section{Effect of initial concentration of dye solution}

The initial concentration provides an important driving force to overcome all mass transfer resistances of the dye between aqueous and solid phases. The adsorption capacity of DCTS for AB 9 as a function of initial dye concentration is shown in Figure 3. Initial concentration of dye has an important role on the adsorption capacity. The initial concentrations of dye solution were varied within the range of 600-3000 $\mathrm{mg} / \mathrm{L}$. It was observed that the adsorption capacity of DCTS sharply increased with increasing the initial concentration of the dye solution and then reached a plateau, indicating the saturation of active sites of the adsorbents i.e. maximum adsorption of the adsorbents reached. As shown in Figure 3, the adsorption capacity of DCTS sharply increased from $280.45 \mathrm{mg} / \mathrm{g}$ to $1151.23 \mathrm{mg} / \mathrm{g}$ with increasing dye concentration from $600 \mathrm{mg} / \mathrm{L}$ to $2400 \mathrm{mg} / \mathrm{L}$ and remained almost constant with further increase in the dye concentration. The adsorption capacity of DCTS for AB 9 was observed to be much higher than the previously reported one for chitosan, $350 \mathrm{mg} / \mathrm{g}$ [31].

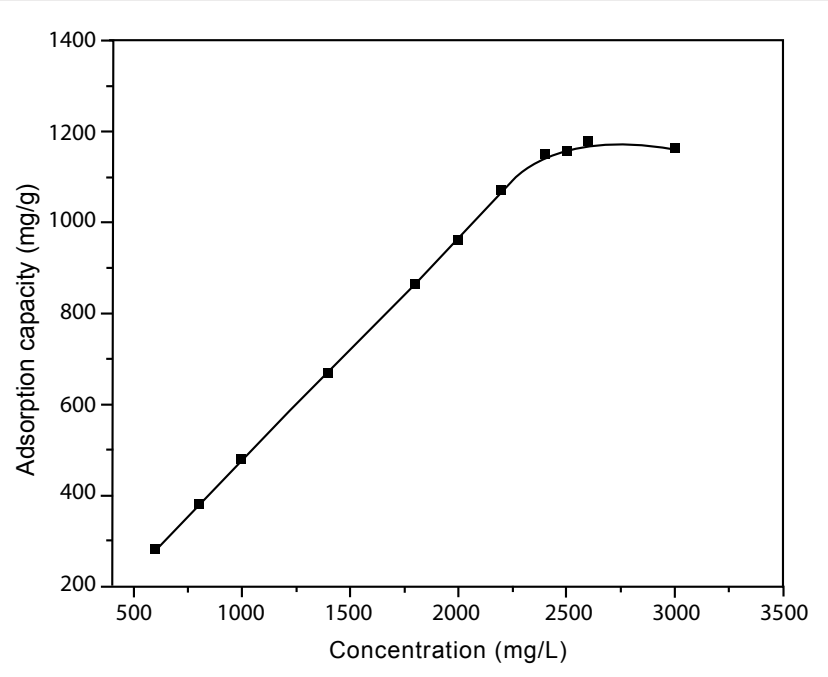

Figure 3: Effect of initial dye concentration on acid blue 9 adsorption by ATCTSD. 
Citation: Sarkar K, Banerjee SL, Kundu PP (2012) Removal of Anionic Dye in Acid Solution by Self Crosslinked Insoluble Dendronized Chitosan. Hydrol Current Res 3:133. doi:10.4172/2157-7587.1000133

Page 5 of 9
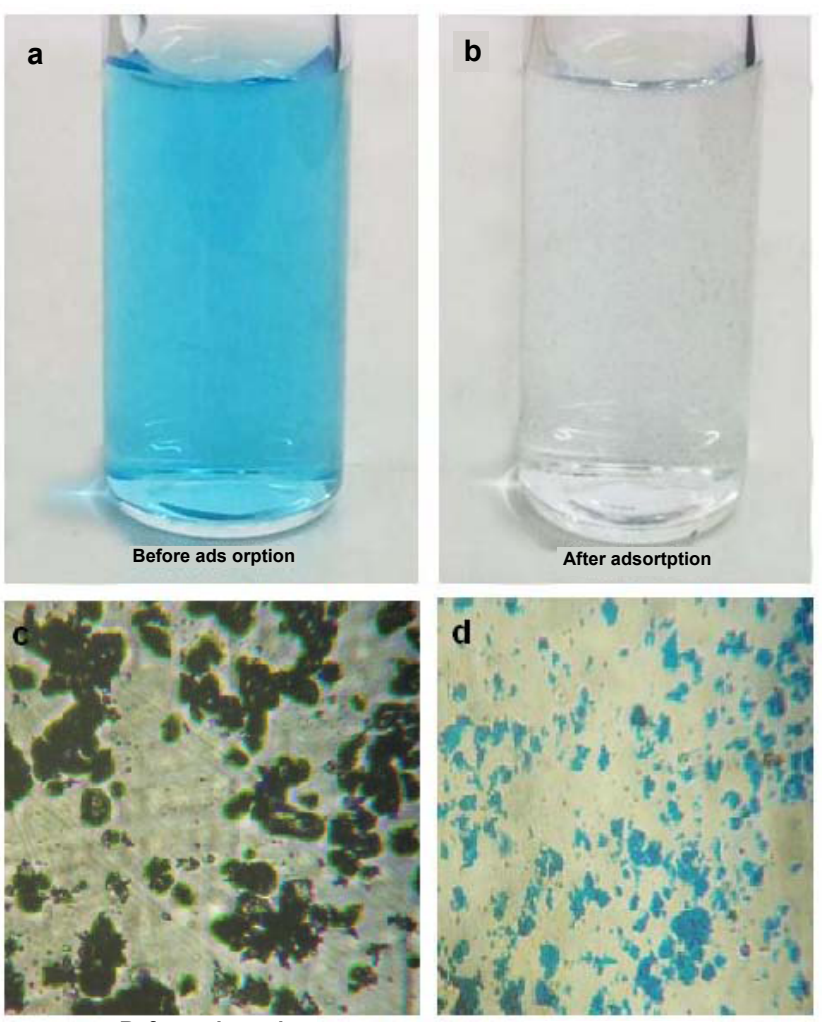

Before adsorption

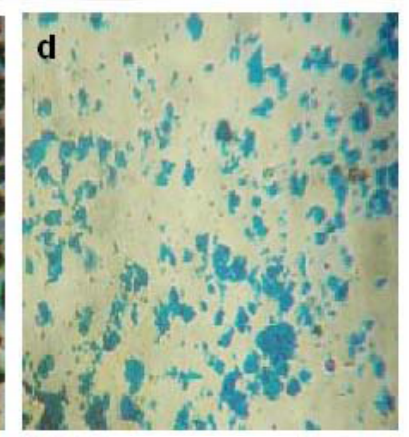

After adsorption

Figure 4: Photographs of $A B 9$ solution (a) before adsorption and (b) after adsorption and microscopic images of ATCTSD (c) before adsorption and (d) after adsorption (temperature $30^{\circ} \mathrm{C} ; \mathrm{pH}$ of solution 4.0; initial concentration of the dye $10 \mathrm{mg} / \mathrm{L}$ ).

\section{Adsorption kinetics}

To further study the adsorption of AB 9, $50 \mathrm{mg}$ DCTS was placed in $\mathrm{pH} 4.0$ aqueous solutions of anionic $\mathrm{AB} 9(10 \mathrm{mg} / \mathrm{L})$ and allowed to equilibrate for $24 \mathrm{hr}$ at $30^{\circ} \mathrm{C}$. Figure $4 \mathrm{a}$ and $4 \mathrm{~b}$ show the change of color of the $\mathrm{AB} 9$ solution and DCTS during the adsorption process. After $24 \mathrm{hr}$, the aqueous solution of $\mathrm{AB} 9$ became colorlessness compared to the original bluish solution (Figure $4 \mathrm{a}$ and $4 \mathrm{~b}$ ). At the same time, DCTS became bluish after adsorption (Figure 4d). This phenomenon confirmed that DCTS could adsorb AB 9 completely from the anionic AB 9 solution.

Figure 5 shows the adsorption of AB 9 onto DCTS as a function of contact time. As observed in Figure 5, the adsorption of $\mathrm{AB} 9$ on DCTS occurred in two phases, firstly a rapid phase, followed by a slow phase. The first phase involved a rapid adsorption of dye during the first $30 \mathrm{~min}$, followed by a slow phase of dye removal spread over a significantly longer period of time (>120 min), until the equilibrium was reached. According to the previous study [32], the rapid phase may last for several minutes to a few hours, while the slow stage continues for several hours to a day. The rapid phase probably occurs due to the availability of more active sites on the adsorbent. The active sites are gradually decreased by the occupancy of adsorbate and result in the slower phase.

To examine the kinetic mechanism of the adsorption process of $A B$ 9 on DCTS, pseudo-first-order and the pseudo-second-order kinetic models are used to test the experimental data. The pseudo-first-order rate equation of Lagergren model [33] is as follows:

$$
\log \left(q_{e}-q_{t}\right)=\log q_{e}-\frac{k_{1} t}{2.303}
$$

The pseudo-second-order rate equation is given as below [34]:

$$
\frac{t}{q_{t}}=\frac{1}{k_{2} q_{e}^{2}}+\frac{t}{q_{e}}
$$

Where $q_{e}$ and $q_{t}$ are the adsorption capacity $(\mathrm{mg} / \mathrm{g})$ at equilibrium and at time $t(\mathrm{~min})$, respectively. $k_{1}\left(\mathrm{~min}^{-1}\right)$ and $k_{2}\left(\mathrm{~g} \mathrm{mg}^{-1} \mathrm{~min}^{-1}\right)$ are the adsorption rate constants of pseudo-first-order and pseudo-secondorder adsorption rates, respectively. The linear plot of $\log \left(q_{e}-q_{t}\right)$ versus $t$ for pseudo-first-order model (Figure 6a) and that of $\left(t / q_{t}\right)$ versus $t$ for pseudo-second-order model (Figure 6b) are drawn. The values of $q_{e}$ and the rate constants $k_{1}$ and $k_{2}$ are obtained from the plot of experimental data.

Table 2 shows the values of calculated $q_{e}$ and the rate constants for pseudo-first-order and pseudo-second-order models. The values of $q_{e}$ and rate constant for pseudo-first-order are $507.87 \mathrm{mg} \mathrm{g}^{-1}$ and $1.51 \times 10^{-}$ ${ }^{2} \mathrm{~min}^{-1}$, respectively and that for pseudo-second-order models are $1254.14 \mathrm{mg} \mathrm{g}^{-1}$ and $9.55 \times 10^{-4} \mathrm{~g} \mathrm{mg}^{-1} \mathrm{~min}^{-1}$, respectively. The values of correlation coefficient $\left(r^{2}\right)$ of pseudo-first-order and pseudo-secondorder models are 0.7286 and 0.9999 , respectively. The calculated $q_{e}$ value of the pseudo-second-order model is $1254.14 \mathrm{mg} / \mathrm{g}$, which is close to the experimental data $(1264.95 \mathrm{mg} / \mathrm{g})$. The higher value of correlation coefficient (0.9999) and the close calculated $q_{e}$ value indicate that these data are well fitted for pseudo-second order model. On the other hand, the theoretical $q_{e}$ value $(507.87 \mathrm{mg} / \mathrm{g}$ ) obtained from the pseudo-firstorder model is significantly different from the experimental data and the correlation coefficient was also found to be lowered value (0.7286) than that of pseudo-second-order model. These results indicate that the adsorption of AB 9 on DCTS is not following the pseudo-first-order kinetic. Thus, it is suggested that the adsorption of AB 9 obeys the pseudo-second-order kinetics.

\section{Adsorption isotherms modeling}

Adsorption isotherms are important for the description of how molecules of adsorbate interact with adsorbent surface. Hence, the correlation of equilibrium data of either a theoretical or an empirical

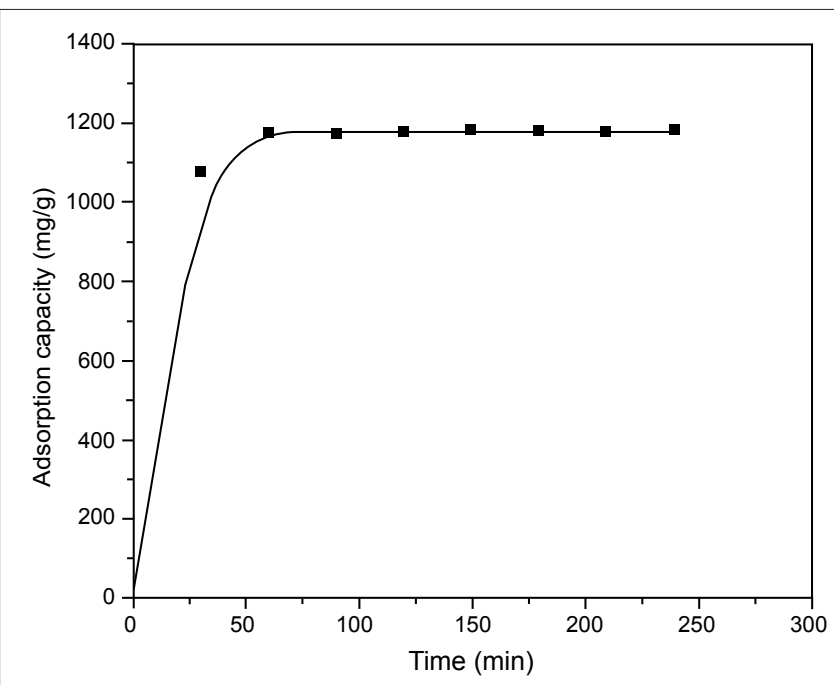

Figure 5: Time profile of $A B 9$ adsorption onto ATCTSD at $25^{\circ} \mathrm{C}$ in $\mathrm{pH} 4.0$ solution. 
Citation: Sarkar K, Banerjee SL, Kundu PP (2012) Removal of Anionic Dye in Acid Solution by Self Crosslinked Insoluble Dendronized Chitosan. Hydrol Current Res 3:133. doi:10.4172/2157-7587.1000133
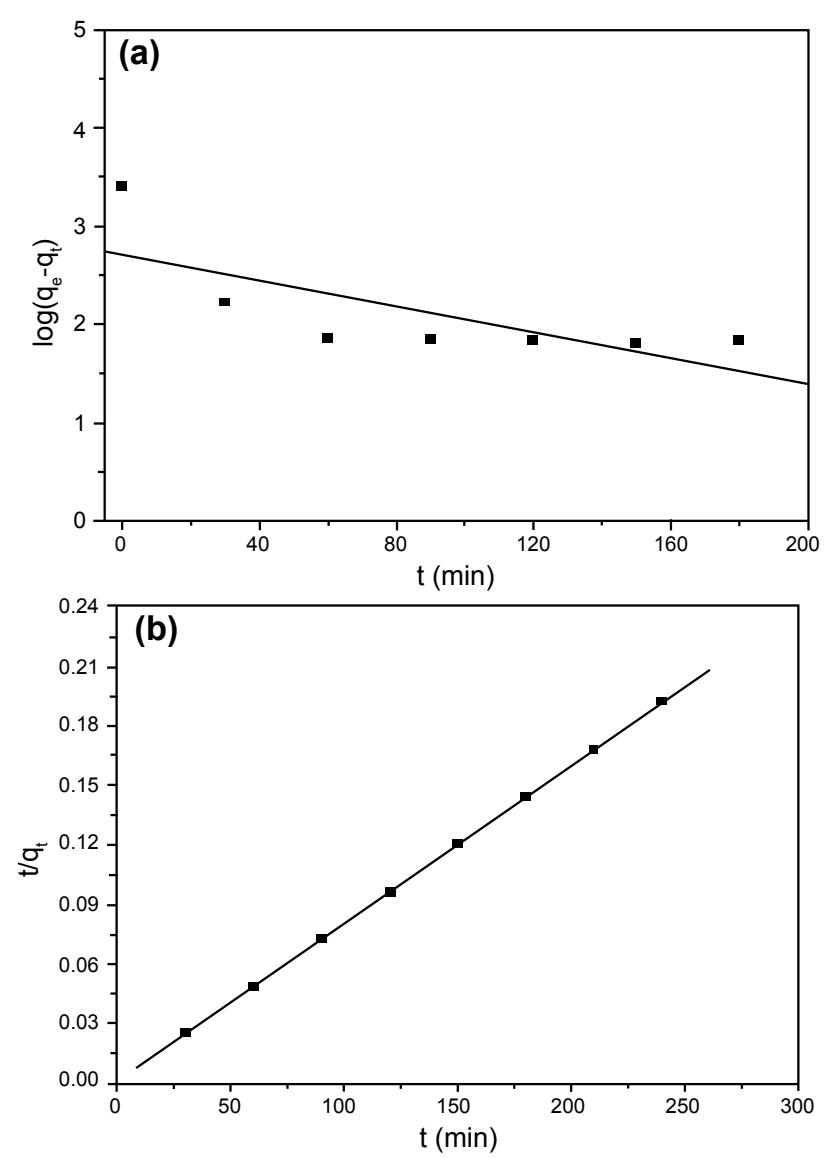

Figure 6: Linearized pseudo-first-order plot for the adsorption of $A B 9$ by ATCTSD (a) and Linearized pseudo-second-order plot for the adsorption of AB 9 by ATCTSD (b).

\begin{tabular}{|c|c|c|c|c|c|c|}
\hline $\begin{array}{c}\text { Experimental } \mathrm{q}_{\mathrm{e}} \\
\left(\mathrm{mg} \mathrm{g}^{-1}\right)\end{array}$ & \multicolumn{3}{|c|}{ Pseudo-first-order constants } & \multicolumn{3}{|c|}{$\begin{array}{c}\text { Pseudo-second-order } \\
\text { constants }\end{array}$} \\
\hline & $\mathrm{q}_{\mathrm{e}}\left(\mathrm{mg} \mathrm{g}^{-1}\right)$ & $\begin{array}{c}K_{1}\left(\times 10^{-2}\right. \\
\left.\mathrm{min}^{-1}\right)\end{array}$ & $\mathrm{r}^{2}$ & $\mathrm{q}_{\mathrm{e}}\left(\mathrm{mg} \mathrm{g}^{-1}\right)$ & $\begin{array}{l}K_{1}\left(\times 10^{-4} \mathrm{~g}\right. \\
\left.\mathrm{mg}^{-1} \mathrm{~min}^{-1}\right)\end{array}$ & $\mathrm{r}^{2}$ \\
\hline 1264.95 & 507.87 & 1.51 & 0.7286 & 1254.14 & 9.55 & 0.9999 \\
\hline
\end{tabular}

Table 2: Comparison of the first-order adsorption, second-order adsorption, intraparticle diffusion rate constants, calculated $\mathrm{q}_{\mathrm{e}}$ and experimental $\mathrm{q}_{\mathrm{e}}$.

equation is essential for the adsorption interpretation and prediction of the extent of adsorption. The obtained adsorption data are interpreted by the two well known isotherm equations namely, the Langmuir and the Freundlich isotherm equations [35].

The Langmuir isotherm equation can be represented as:

$$
\frac{C_{e}}{q_{e}}=\frac{1}{q_{\max } b}+\frac{C_{e}}{q_{\max }}
$$

Where, $b$ is the adsorption equilibrium constant $(\mathrm{L} / \mathrm{mg})$ and $q_{\max }$ is the maximum dye adsorption capacity $(\mathrm{mg} / \mathrm{g})$. The values of $q_{\max }$ and $b$ can be obtained from linear plot of $C_{e} / q_{e}$ versus $C_{e}$.

The Freundlich isotherm equation based on adsorption on a heterogeneous surface is given as follows:

$$
q_{e}=K_{F} \times C_{e}^{1 / n}
$$

This equation can be rewritten as below for its linearized form:

$$
\ln q_{e}=\ln K_{F}+\frac{1}{n} \ln C_{e}
$$

Where, $K_{F}$ and $n$ are the Freundlich constants, which represent adsorption capacity and adsorption intensity, respectively. $K_{F}$ and $n$ can be obtained from the intercept and slope of a linear plot of $l n q_{e}$ against $\ln C_{e}$.

A linear plot of $C_{e} / q_{e}$ versus $C_{e}$ for the Langmuir model of adsorption of AB 9 on DCTS is shown in Figure 7a. Figure $7 \mathrm{~b}$ shows the linear plot of Freundlich isotherm model for the adsorption of AB 9 on DCTS. From Table 3, it is found that the calculated values of $q_{\max }, b$ and $R_{L}$ for Langmuir model are $1264.03 \mathrm{mg} \mathrm{g}^{-1}, 0.121 \mathrm{~L} \mathrm{mg}^{-1}$ and 0.004 , respectively and the calculated values of $K_{F}$ and $1 / n$ for Freundlich model are 447.6 $\left(\mathrm{mg} \mathrm{g}^{-1}\right) /\left(\mathrm{mg} \mathrm{L}^{-1}\right)^{1 / \mathrm{n}}$ and 0.157 , respectively. The values of correlation coefficient $\left(r^{2}\right)$ of Langmuir and Freundlich models are 0.99028 and 0.8499 , respectively. These correlation coefficients of the linearized form of both the Langmuir and Freundlich adsorption equations indicate that the Langmuir model yields a better fit for the experimental equilibrium adsorption data than that of the Freundlich model. This result suggests the monolayer coverage of the dye on the surface of the DCTS. The maximum adsorption of AB 9 on DCTS is found to be $1264.03 \mathrm{mg} / \mathrm{g}$ (from the plot), which is equal to the experimental
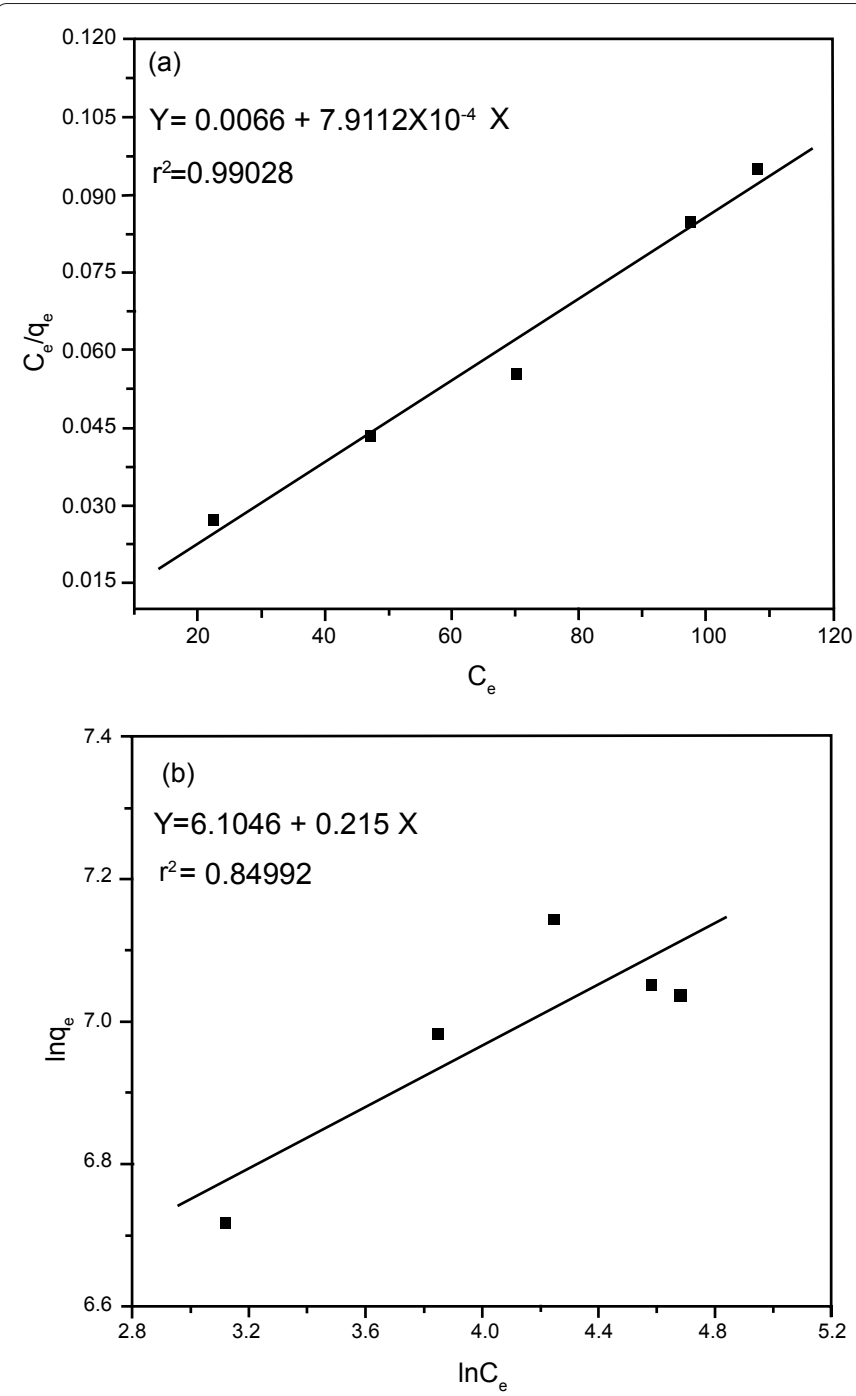

Figure 7: The linearized Langmuir adsorption isotherms for the adsorption of acid blue 9 by ATCTSD and the linearized Freundlich adsorption isotherms for the adsorption of acid blue 9 by ATCTSD (b). 
Citation: Sarkar K, Banerjee SL, Kundu PP (2012) Removal of Anionic Dye in Acid Solution by Self Crosslinked Insoluble Dendronized Chitosan. Hydrol Current Res 3:133. doi:10.4172/2157-7587.1000133

Page 7 of 9

\begin{tabular}{|c|c|c|c|c|c|c|c|}
\hline $\begin{array}{c}\text { Experimental } \\
\left(\mathrm{mg} \mathrm{g}^{-1}\right)\end{array}$ & \multicolumn{5}{|c|}{ Langmuir } & \multicolumn{3}{c|}{ Freundlich } \\
\hline & $\begin{array}{c}\mathrm{q}_{\max } \\
\left(\mathrm{mg} \mathrm{g}^{-1}\right)\end{array}$ & $\begin{array}{c}b \\
\left(\mathrm{Lg} \mathrm{m}^{-1}\right)\end{array}$ & $\mathrm{R}_{\mathrm{L}}$ & $\mathrm{r}^{2}$ & $\begin{array}{c}\mathrm{K}_{\mathrm{F}}\left[\left(\mathrm{mg} \mathrm{g}^{-1}\right) /\right. \\
\left.\left(\mathrm{mg} \mathrm{L}^{-1}\right)^{1 / n}\right]\end{array}$ & $1 / \mathrm{n}$ & $\mathrm{r}^{2}$ \\
\hline 1264.95 & 1264.03 & 0.121 & 0.004 & 0.9903 & 447.6 & 0.157 & 0.8499 \\
\hline
\end{tabular}

Table 3: The Langmuir and Freundlich isothermsmodel constants and their respective correlation coefficients $\left(R^{2}\right)$ for the sorption of acid blue 9 from aqueous solution by DCTS.

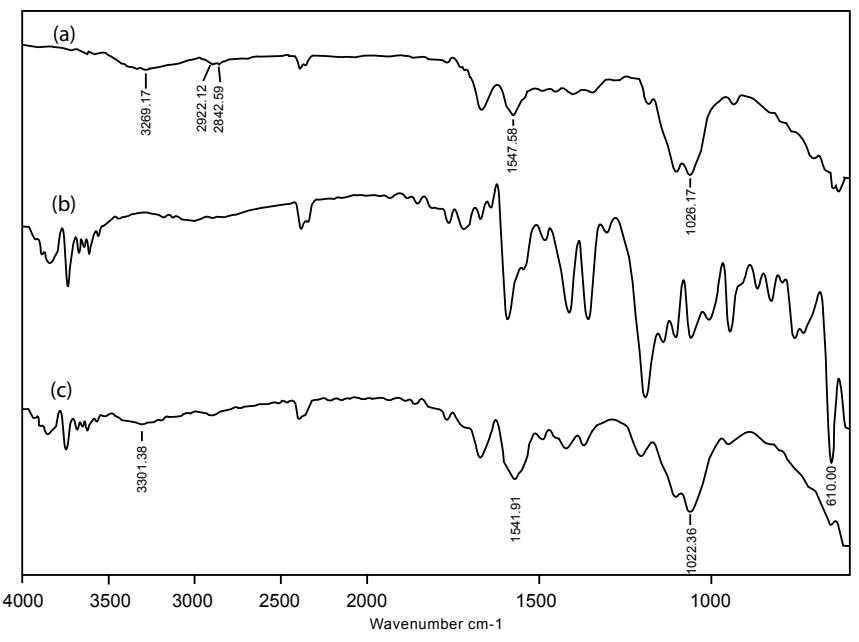

Figure 8: FT-IR spectrum of ATCTSD: before adsorption (a) and after adsorption (c) as well as acid blue 9 (b).

data $(1264.95 \mathrm{mg} / \mathrm{g})$. Dendronization of chitosan increased the maximum adsorption capacity of chitosan from $350 \mathrm{mg} / \mathrm{g}$ to 1264.95 $\mathrm{mg} / \mathrm{g}$ [31]. Previous report showed the maximum adsorption capacity of crosslinked chitosan (crosslinked by ethylene glycol diglycidyl ether, EDGE) for acid red 37 (AR 37) and acid blue 25 (AB 25) dye was 59.52 and $142.86 \mathrm{mg} / \mathrm{g}$, respectively [28]. In that report, it was found that the adsorption capacity of modified chitosan decreased than that of parent chitosan. This phenomenon may be explained by the fact that the primary amine groups of chitosan engaged for inter molecular crosslinking, which lowered the active adsorption site resulting lower adsorption capacity. Similar result was observed in another work [36]. But, in this study the insoluble dendronized chitosan was obtained during the course of reaction by intra- and inter-molecular crosslinking without any external crosslinking agent and at the same time, the number of primary amine increased by dendronization of chitosan. As a result, the number of active adsorption site increased and resulted higher adsorption capacity of DCTS. Sing et al. [37], observed similar type result. They prepared poly(acrylamide) functionalized chitosan for the removal of azo dyes, Remazol brilliant Violet (RV) and Procion Yellow (PY) and they obtained maximum adsorption capacity 1428.57 and $1000.00 \mathrm{mg} / \mathrm{g}$ for RV and PY, respectively. Therefore, DCTS may be used as most effective adsorbent for the separation of acid dye from waste water.

The affinity between the adsorbate and adsorbent can be obtained from the Langmuir parameter with the help of the dimensionless separation factor $\left(\mathrm{R}_{\mathrm{L}}\right)$, which can be presented as below [38].

$$
R_{L}=\frac{1}{1+b C_{i}}
$$

In accordance with criteria of $\mathrm{R}_{\mathrm{L}}\left(\mathrm{R}_{\mathrm{L}}>1\right.$ : unfavorable; $\mathrm{R}_{\mathrm{L}}=1$ : linear; $0>R_{L}<1$ : favorable and $R_{L}=0$ : irreversible), $R_{L}$ can be used to predict whether an adsorption system is "favorable" or "unfavorable". The $\mathrm{R}_{\mathrm{L}}$ value for this adsorption system is 0.004 , which is lower than 1 and higher than zero. This suggests that the adsorption of $\mathrm{AB} 9$ onto DCTS is "favorable".

\section{Proposed adsorption mechanism}

The adsorption of AB 9 dye on DCTS was analyzed using FT-IR spectroscopy and the spectrum is depicted in Figure 8. Decolorization may occur through adsorption or activated adsorption and the latter is electrostatic adsorption due to charged surface of adsorbent and ionic adsorbate species. Many physiochemical factors such as, dye/adsorbent interaction, adsorbent surface area, particle size, temperature, $\mathrm{pH}$ and contact time may influence the adsorption process.

FT-IR spectrophotometry was performed to elucidate the active site of the adsorbent. Figure 8a shows two strong peaks at $1641.9 \mathrm{~cm}^{-1}$ and $1547.6 \mathrm{~cm}^{-1}$ which are assigned to the presence of primary amine groups and N-H bending vibration of amine-terminated DCTS, respectively. The absorption peaks at 2866.8 and $2922.1 \mathrm{~cm}^{-1}$ are characteristic of the methylene group and the peak at $1026.2 \mathrm{~cm}^{-1}$ is characteristic of the tertiary amino group of amine-terminated DCTS. A broad and strong band is observed from 3000 to $3600 \mathrm{~cm}^{-1}$, indicating the presence of free or hydrogen bonded $\mathrm{O}-\mathrm{H}$ groups and $\mathrm{N}-\mathrm{H}$ groups of the adsorbent, DCTS. The bands at $2922.1 \mathrm{~cm}^{-1}$ and $2842.6 \mathrm{~cm}^{-1}$ are assigned to the stretching of symmetric or asymmetric $\mathrm{C}-\mathrm{H}$ vibration of methyl and methylene groups, respectively. The absorption band at $1065.4 \mathrm{~cm}^{-1}$ is attributed to the stretching vibration of the second $-\mathrm{OH}$ group. This
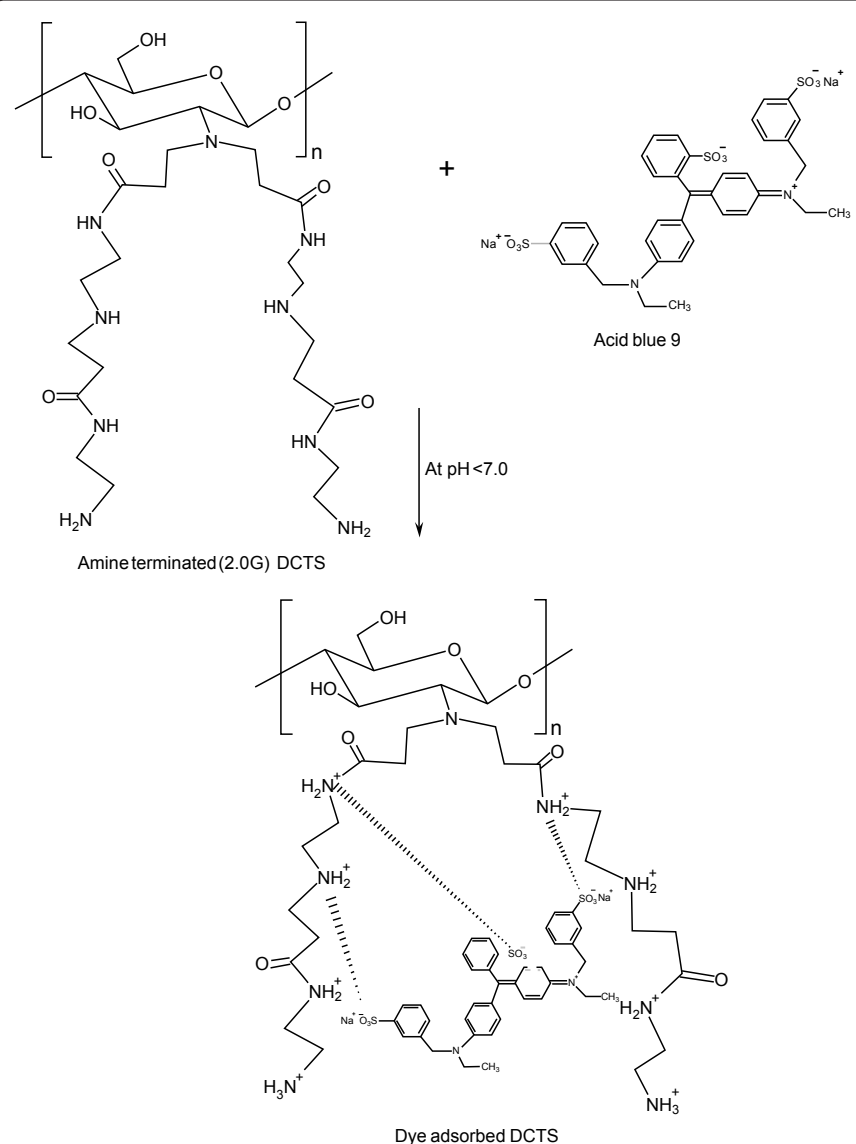

Scheme 3: The proposed mechanism of AB 9 adsorption onto ATCTSD. 


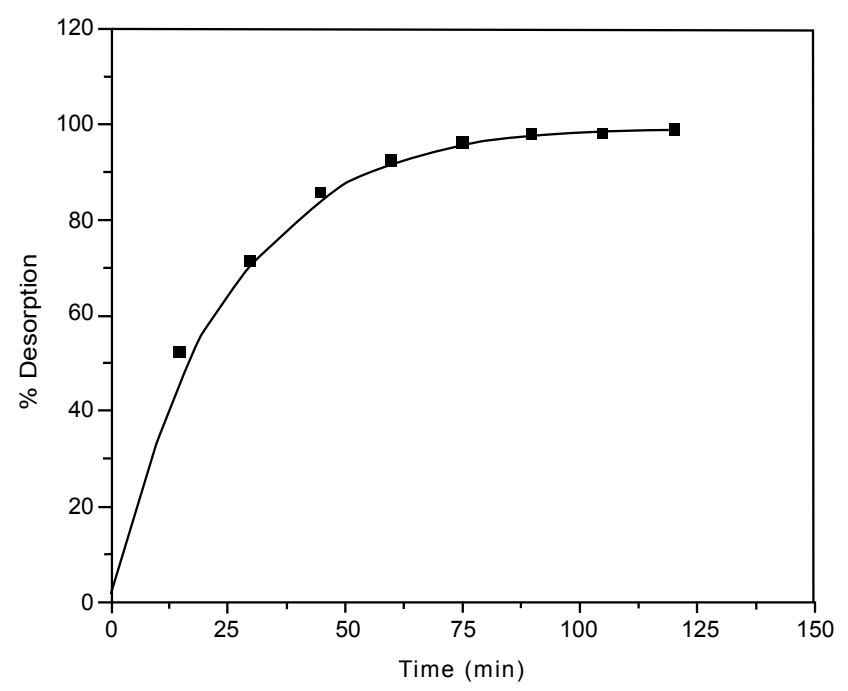

Figure 9: Desorption of AB 9 from dye-loaded ATCTSD at different times.

FT-IR spectrum indicates the presence of primary and tertiary amino groups and hydroxyl groups in DCTS skeleton. The adsorption of AB 9 on the DCTS may be due to the presence of electrostatic attraction between these groups and the sulfonic groups of the anionic dye molecule ( $\mathrm{AB} 9$ ). When the $\mathrm{pH}$ of $\mathrm{AB} 9$ solution is lower than 7 , the charge at the surface of DCTS becomes positive and the adsorption of $\mathrm{AB} 9$ on DCTS occurs due to electrostatic interaction. Figure $8 \mathrm{c}$ shows one absorption band at $3269.2 \mathrm{~cm}^{-1}$ assigned for O-H and $\mathrm{N}-\mathrm{H}$ groups, shifts to the higher wave number $\left(3301.4 \mathrm{~cm}^{-1}\right)$ after adsorption. On adsorption, the strong peak at $1547.6 \mathrm{~cm}^{-1}$ (N-H bending vibration of primary amine groups of DCTS) shifts to wave numbers $1541.9 \mathrm{~cm}$ ${ }^{1}$, respectively. This confirms that the adsorption of AB 9 by DCTS is an ion exchange process between the positively charged groups of DCTS and the anionic dye molecule. The proposed mechanism of AB 9 adsorption on DCTS is shown in Scheme 3.

\section{Desorption study}

To evaluate the economic viability of adsorbent for water purification, it is necessary to re-generate the spent adsorbent. Figure 9 illustrates the desorption of AB 9 from DCTS at different time intervals. For desorption, the reaction responsible may be as follows:

$$
\mathrm{R}-\mathrm{NH}_{3}{ }^{+} \mathrm{AB}-\mathrm{SO}_{3}^{-}+\mathrm{NaOH} \rightarrow \mathrm{R}-\mathrm{NH}_{2}+\mathrm{AB}_{-} \mathrm{SO}_{3} \mathrm{Na}+\mathrm{H}_{2} \mathrm{O}
$$

It is found from Figure 9 that the desorption process was reasonably fast and the equilibrium was almost reached within 60 minutes and almost total dye (98.95\%) was desorbed from DCTS within $2 \mathrm{hr}$ even after three cycles of desorption studies. DCTS showed better desorption results compared to the previously reported system, chitosan-EDGE [28] and poly (acrylamide) functionalized chitosan [37].

The insoluble DCTS used in this study were reused without any loss of their adsorption capacity (data not shown).

\section{Conclusions}

Surface modification of chitosan with dendrimer like PAMAM makes it insoluble material at any $\mathrm{pH}$ and consequently the adsorption capacity of dendronized CTS increased sharply from $350 \mathrm{mg} / \mathrm{g}$ to 1265 $\mathrm{mg} / \mathrm{g}$. Adsorption of the anionic dye AB 9 on insoluble DCTS followed the Langmuir model rather than Freundlich model. The adsorption process is endothermic in nature. The adsorption capacity of DCTS depends on initial dye concentration, $\mathrm{pH}$, temperature and time. The adsorption process was very fast initially, attained equilibrium within a few hours and followed the pseudo-second-order kinetic rate model. The treated DCTS adsorbent is found to be recyclable. Therefore, it may be concluded that the dendronized chitosan can be used as promising biosorbent for anionic dye removal from dye waste water.

\section{References}

1. Elwakeel KZ (2009) Removal of Reactive Black 5 from aqueous solutions using magnetic chitosan resins. J Hazard Mater 167: 383-392.

2. Annadurai G, Ling LY, Lee JF (2008) Adsorption of reactive dye from an aqueous solution by chitosan: isotherm, kinetic and thermodynamic analysis. $J$ Hazard Mater 152: 337-346.

3. Gupta VK, Suhas (2009) Application of low-cost adsorbents for dye removal: A review. J Environ Manage 90: 2313-2342.

4. Srinivasan A, Viraraghavan $T$ (2010) Decolorization of dye wastewaters by biosorbents: A review. J Environ Manage 91: 1915-1929.

5. Panswed J, Wongchaisuwan S (1986) Mechanism of dye wastewater color removal by magnesium carbonate-hydrated basic. Water Sci Technol 18: 139144

6. Ciardelli G, Corsi L, Marucci M (2000) Membrane separation for wastewater reuse in the textile industry. Resour Conserv Recycl 31: 189-197.

7. Alinsafi A, Khemis M, Pons MN, Leclerc JP, Yaacoubi A, et al. (2005) Electro-coagulation of reactive textile dyes and textile wastewater. Chemical Engineering and Processing: Process Intensification 44: 461-470.

8. Nyholm N, Jacobsen BN, Pedersen BM, Poulsen O, Damborg A, et al. (1992 Removal of organic micropollutants at ppb levels in laboratory activated sludge under various operating conditions. Water Res 26: 339-353.

9. Crini G (2006) Non-conventional low-cost adsorbents for dye removal: A review Bioresour Technol 97: 1061-1085.

10. Sakkayawong N, Thiravetyan P, Nakbanpote W (2005) Adsorption mechanism of synthetic reactive dye wastewater by chitosan. J Colloid Interface Sci 286 : 36-42.

11. Babel S, Kurniawan TA (2003) Low-cost adsorbents for heavy metals uptake from contaminated water: A review. J Hazard Mater 97: 219-243.

12. Chairat M, Rattanaphani S, Bremner JB, Rattanaphani V (2008) Adsorption kinetic study of lac dyeing on cotton. Dyes and Pigments 76: 435-439.

13. Ponnusami V, Vikram S, Srivastava SN (2008) Guava (Psidium guajava) leaf powder: Novel adsorbent for removal of methylene blue from aqueous solutions. J Hazard Mater 152: 276-286.

14. Han R, Ding D, Xu Y, Zou W, Wang Y, et al. (2008) Use of rice husk for the adsorption of congo red from aqueous solution in column mode. Bioresour Technol 99: 2938-2946.

15. Cheung WH, Szeto YS, McKay G (2007) Intraparticle diffusion processes during acid dye adsorption onto chitosan. Bioresour Technol 98: 2897-2904.

16. Chang MY, Juang RS (2004) Adsorption of tannic acid, humic acid, and dyes from water using the composite of chitosan and activated clay. J Colloid Interface Sci 278: 18-25.

17. Synowiecki J, Al-Khateeb NA (2003) Production, properties, and some new applications of chitin and its derivatives. Crit Rev Food Sci Nutr 43: 145-171.

18. Vieira RS, Beppu MM (2006) Interaction of natural and crosslinked chitosan membranes with $\mathrm{Hg}(\mathrm{II})$ ions. Colloids Surf A Physicochem Eng Aspects 279 : 196-207.

19. Sherbiny IME (2009) Synthesis, characterization and metal uptake capacity of a new carboxymethyl chitosan derivative. Eur Polym J 45: 199-210.

20. Han R, Zhang L, Song C, Zhang M, Zhu H, et al. (2010) Characterization of modified wheat straw, kinetic and equilibrium study about copper ion and methylene blue adsorption in batch mode. Carbohy Polym 79: 1140-1149.

21. Wong YC, Szeto YS, Cheung WH, McKay G (2004) Adsorption of acid dyes on chitosan equilibrium isotherm analyses. Process Biochem 39: 695-704. 
Citation: Sarkar K, Banerjee SL, Kundu PP (2012) Removal of Anionic Dye in Acid Solution by Self Crosslinked Insoluble Dendronized Chitosan. Hydrol Current Res 3:133. doi:10.4172/2157-7587.1000133

22. Chiou MS, Li HY (2003) Adsorption behavior of reactive dye in aqueous solution on chemical cross-linked chitosan beads. Chemosphere 50: 1095-1105.

23. Cestari AR, Vieira EFS, dos Santos AGP, Mota JA, de Almeida VP (2004) Adsorption of anionic dyes on chitosan beads. 1. The influence of the chemical structures of dyes and temperature on the adsorption kinetics. J Colloid Interface Sci 280: 380-386.

24. Chiou MS, Ho PY, Li HY (2004) Adsorption of anionic dyes in acid solutions using chemicallycross-linked chitosan beads. Dyes and Pigments 60: 69-84.

25. Kamari A, Wan Ngah WS, Chong MY, Cheah ML (2009) Sorption of acid dyes onto GLA and H2SO4 cross-linked chitosan beads. Desalination 249: 11801189.

26. Tsubokawa N, Takayama T (2000) Surface modification of chitosan powder by grafting of dendrimer-like hyperbranched polymer onto the surface. React Funct Polym 43: 341-350.

27. Ramakrishnan M, Nagarajan S (2009) Utilization of waste biomass for the removal of basic dye from water. World Appl Sci J 5: 114-121.

28. Kamari A, Wan NWS, Liew LK (2009) Chitosan and chemically modified chitosan beads for acid dyes sorption. J Environ Sci 21: 296-302.

29. Bhattacharyya KG, Sarma A (2003) Adsorption characteristics of the dye, brilliant green, on neem leaf powder. Dyes \& Pigments 57: 211-222.

30. Wang L, Zhang J, Wang A (2011) Fast removal of methylene blue from aqueous solution by adsorption onto chitosan-g-poly (acrylic acid)/attapulgite composite. Desalination 266: 33-39.
31. Dotto GL, Pinto LAA (2010) Adsorption of food dyes acid blue 9 and food yellow 3 onto chitosan: Stirring rate effect in kinetics and mechanism. J Hazard Mater 187: 164-170.

32. Saeed A, Iqbal M, Zafar SI (2009) Immobilization of Trichoderma viride for enhanced methylene blue biosorption: batch and column studies. J Hazard Mater 168: 406-415.

33. Lagergren $S$ (1898) About the theory of so-called adsorption of soluble substances. Handlingar 24: 1-39.

34. Ho YS, McKay G (1999) Pseudo-second order model for sorption processes. Process Biochem 34: 451-465.

35. Periasamy K, Namasivayam C (1995) Removal of nickel(II) from aqueous solution and nickel plating industry wastewater industry using an agriculture waste: peanut hull. Waste Manage 15: 63-68.

36. Kamari A, Ngah WSW, Chong MY, Cheah ML (2009) Sorption of acid dyes onto GLA and H2SO4 cross-linked chitosan beads. Desalination 249: 1180-1189.

37. Singh V, Sharma AK, Sanghi R (2009) Poly(acrylamide) functionalized chitosan: An efficient adsorbent for azo dyes from aqueous solutions. J Hazard Mater 166: 327-335.

38. Hall KR, Eagleton LC, Acrivos A, Vermeulen T (1996) Pore- and solid-diffusion kinetics in fixed-bed adsorption under constant-pattern conditions. Ind Eng Chem Fundam 5: 212-223. 